\title{
Knowledge and attitude regarding HIV/AIDs among sexual minorities of Kathmandu
}

\section{Sharma $\mathbf{S}^{1}$}

'Sumitra Sharma, Lecturer, Department of Nursing, Kathmandu Medical College Teaching Hospital, Sinamangal, Kathmandu, Nepal

\section{Abstract}

Background: Sexual minorities are at high risk of contracting and spreading HIV/AIDS. Several studies in Nepal and around the world depict issues of HIV/AIDS and other problems of sexual minorities.

Objective: The present study was carried out with the aim to investigate and evaluate knowledge and attitude of sexual minorities regarding HIV/AIDS.

Methods: A cross-sectional study was conducted for a period of eight months starting from June 2009. Sixty six respondents accomplished quantitative interviews and face-to-face interviewer-administered demographic, knowledge and attitude of HIV/AIDS survey. Descriptive and inferential analysis was done using Statistical Package for Social Sciences version 16. A five point Likert scale was used to assess attitude of the respondents. Pearson's chi-square test was used to compare the association between knowledge and selected socio-demographic variables. Spearman's correlation test was used to make out the degree of relationship between knowledge and attitude.

Results: Among 66 sexual minorities, 34.84\% were gay, 28.78\% were transgender, $25.75 \%$ were bisexuals and $10.60 \%$ were lesbians. Nearly $47 \%$ of the respondents showed adequate knowledge with mean knowledge score of 29 . With the mean attitude score of $39,45.5 \%$ showed positive attitude towards HIV infection. The findings depicted an association between knowledge and participation of respondents on training/awareness program $(p<0.05)$. Also, data exemplified proportionate relationship between level of knowledge and attitude of a person towards the disease.

Conclusion: Existing knowledge among the respondents was enhanced by the influence of training and awareness program. Also, the level of knowledge determined an attitude of a person toward HIV infected people and vice versa.
\end{abstract}

Key words: Attitude, HIV/AIDS, Knowledge, Sexual Minorities

\section{INTRODUCTION}

$\mathrm{H}$ uman Immunodeficiency Virus (HIV) continues to spread among LGBT [Lesbian, Gay (Homosexual Men), Bisexual and Transgender] worldwide. Given the special risk associated with anal sex, the prevalence of HIV is more likely to be significantly worse among homosexuals than the general population. Globally gay/ homosexual men, bisexual and transgender are 19 times more likely to be infected with HIV than the general population ${ }^{1}$. Recently CDC (Centre for Disease Control and Prevention) found that one in five homosexual men and bisexual men in twenty-one major cities of United States were infected with HIV, and nearly half were unaware of their infection. Similarly, the rate of new

Address for correspondence

Ms. Sumitra Sharma

Lecturer, Department of Nursing, Kathmandu Medical College

Teaching Hospital

Sinamangal, Kathmandu, Nepal

E-mail: smtrsharma@gmail.com infection among transgender people is three to nine times higher than the general population².

Prevalence of HIV among MSM (men having sex with men) in low and middle income countries is $12.8 \%{ }^{1}$. Asian countries have not seen explosive epidemics up to now but patterns of increasing infections through homosexuals, transgender, sex workers and intravenous drug users don't provide a room for contentment ${ }^{3}$. MSM in China were more than forty five times more likely than the general population. India has the second highest number of people living with Acquired Immunodeficiency Syndrome (AIDS) in the world ${ }^{4}$. In Nepal, the national HIV prevalence is 0.3 percent among adult aged 15-29 years which has reduced significantly during the last five years. However, the percentage of men having sex with male who are HIV infected is $3.80 \%{ }^{5}$.

While the global conversation focuses on novel approaches to HIV treatment and prevention, LGBT are 
still struggling to obtain the most basic health services. Institutionalized homophobia and criminalization of homosexual activity facilitate the spread of HIV, brutally hindering efforts to provide treatment and prevention for them ${ }^{1}$. In Asian communities, the cultural taboos and legal restriction to LGBT prevents them from their sexual health rights ${ }^{6}$. There are limited literature available regarding LGBT study related public health issues where as only 3777 articles, the equivalent of 0.1 $\%$ of which the MEDLINE database, focused on LGBT individuals over the past 20 years ${ }^{7}$. A recent study from 128 countries found that majority (70\%) of the countries was not able to report on the level of understanding among most risk population of HIV prevalence ${ }^{1}$. Many studies were only limited to prevalence and incidence of HIV among intravenous drug users, sex workers and MSM. The identification alone is not enough, but their level of knowledge and attitude towards the disease is basic for the preclusion in an early stage. In Nepal, it is quite notable that various integrated biological and behavioural surveillance are conducted among sex workers but this does not include all kinds of LGBT population. There is paucity of data where the knowledge and attitude of HIV have been assessed on the basis of their sexual orientation on high risk population. Hence, this study tries to fill the gap.

\section{METHODS}

\section{DESIGN AND SETTING}

Between June and December 2009, an interview was performed to gather the information from semistructured questionnaire from the target population. Study procedures were done at Blue Diamond Society, Parichaya Samaj and Cruiseaids. They are non-profitable dependent national organizations working with and for sexual/gender minorities on social justice, human rights, sexual health and HIV/AIDS. The Kathmandu Medical College Teaching Hospital (KMCTH) institutional review board approved the study and every respondent fulfilled an informed consent procedures. Institutional approval was taken from all the organizations prior to the study.

\section{SAMPLING}

Potential respondents were scrutinized by the researcher herself and the senior administrative officer of the study sites through asking question to establish eligibility. Respondents were qualified for the study if they were: of third gender; self-identified as Lesbian, Gay (Homosexual men), Transgender or Bisexual; and were aged 18 years or older. Both the venue-based employment strategies and chain-referral sampling methods were used to employ respondents. First, venue-based recruitment strategies comprised of outreach and redeployment of research staffs at Blue Diamond Society, Parichaya Samaj and Cruiseaids. Second, chain-referral sampling, where registered respondents referred eligible peers, was also used. The chain-referral process reaches individuals who did not participate in public venues.

\section{DATA COLLECTION AND MEASUREMENTS}

A semi-structured interview schedule was developed as per the objectives of the study based on the researcher's experience, knowledge and observation, review of literature and experts opinion. The interview schedule consisted of 3 parts: the first part included demographic profile viz. age, sex, marital status, education, designation and economic status. Second part consisted of twenty seven semi-structured questionnaire regarding meaning of HIV/AIDS, mode of transmission and its preventive measures and then the level of knowledge is categorized into adequate and inadequate depending upon the mean value of the score. When calculated score was equal to and above the mean value, then the level of knowledge was adequate but when the score is low than the mean value, the level of knowledge was inadequate. Third part consisted of ten structured questionnaire for the attitudes of respondents' toward HIV/AIDS. All the statements were positive and were assessed using five point Likert scale, score ranging from 0-5 for each statement (strongly disagree, disagree, uncertain, agree and strongly agree). The mean value is used as the demarcation for the positive and negative attitude. The logical sequence of questionnaire was maintained and the validity of the tool was ascertained from the guide and experts from Department of Nursing and Department of Community Medicine of KMCTH. The interview tool was developed in both English and Nepali with the help from language experts. The pretesting was done among seven samples (10\% of total sample size) with the staffs of BDS but no modification was required and the same questionnaire was used for the main data collection. Interviews were completed on an average of 60 minutes. Informed consent from individual participant was obtained. Confidentiality and right to withdraw was maintained with voluntary participation.

\section{DATA ANALYSIS}

Data were coded, cleaned and checked for disparities. Descriptive and inferential analysis was done using SPSS (Statistical Package for Social Sciences) version 16. In this study, first round analysis showed that age, occupation, education status, sexual identity were all linked to the likelihood of participating in the survey. In the second round, the probability of association was established through Chi square analysis and finally correlation was 
tested between the knowledge and attitudes towards HIV/AIDS.

\section{RESULTS}

Among 66 respondents, 23 (34.84\%) of them were homosexual men followed by 19 (28.78\%) transgender, 19 (25.75\%) were bisexuals and remaining other lesbians. The median age of respondents was 25 years (range: 17-50 years). Among them, 46 (70\%) of them were unmarried, $15(22.72 \%)$ married and $5(7.57 \%)$ were divorced. In the service sector, 37 (56.06\%) of them were engaged in service, 15 (22.72\%) of them were student, and rest of them were unemployed. All respondents were literate and $46(69.6 \%)$ have received training and awareness program regarding HIV/AIDS.

All of them have heard about HIV and AIDS whereas 56 (85\%) of them replied that it is a communicable disease and $52(79 \%)$ accepted that it is not a hereditary disease. Four fifth of them told that HIV and AIDS are same and HIV causes AIDS. Half of them told that young people are most likely to get infected with HIV/AIDS and 56 (85\%) respondents said weight loss is a major sign of HIV/AIDS. In addition, $16(25 \%)$ of them were not aware about fever and diarrhoea. However, less than $10 \%$ described that abdominal pain, rashes and weakness as other sign and symptoms.

Most of them (98.48\%) knew that HIV can be diagnosed through blood test. When we told to rank major causes of HIV transmission, the data obtained was anal sex 35 (53.03\%) followed by vaginal intercourse $16(24.24 \%)$, oral sex $11(16.6 \%)$ and kisses 4 (6.06\%). They also explained that transgender and sex workers are the high risk group population for HIV/AIDS. All respondents knew that HIV can be transmitted through blood transfusion and sharing needles (Table 1).

\section{Table 1: Knowledge regarding transmission of HIV/} AIDS

\begin{tabular}{ll|}
\hline Statements & $\begin{array}{c}\text { Frequency } \\
\text { (Percent) }\end{array}$ \\
\hline Doesn't transmit from kissing & $60(90.09)$ \\
\hline HIV positive mother can conceive & $31(46.96)$ \\
\hline Transmit from oral sex & $54(81.81)$ \\
\hline Transmit from anal sex & $65(98.48)$ \\
\hline $\begin{array}{l}\text { lesbians susceptible to HIV } \\
\text { Blood test is the most reliable source to } \\
\text { diagnose HIV }\end{array}$ & $49(74.24)$ \\
\hline $\begin{array}{l}\text { Bisexuals as the most risk group among } \\
\text { LGBT }\end{array}$ & $28(98.48)$ \\
\hline
\end{tabular}

All of them knew about safe sex and 61 (92.42\%) knew about Voluntary Counselling and Testing (VCT) services. About 64 (97\%) of them said that use of condom can prevent HIV/AIDS and 11 (16\%) of them told lubricants can also prevent them from HIV.

Regarding the overall knowledge of HIV/AIDS among the respondents, $31(47 \%)$ of them had adequate knowledge whereas 35 (53\%) of them had inadequate knowledge where mean knowledge is taken as a cut-off value which is 29 . Similarly, taking mean value (39) as the point of demarcation for the attitude, $45.5 \%$ showed the positive attitude towards HIV infected person whereas rest of them showed negative attitude (Table 2).

\section{Table 2: Attitude regarding HIV/AIDS}

\begin{tabular}{|c|c|}
\hline $\begin{array}{l}\text { Statements agreed by } \\
\text { participants }\end{array}$ & Frequency (Percent) \\
\hline $\begin{array}{l}\text { When you get infected with HIV/ } \\
\text { AIDS you should discuss about it } \\
\text { with your partner. }\end{array}$ & $66(100)$ \\
\hline $\begin{array}{l}\text { Advertisements regarding safe } \\
\text { sex and condom use must be } \\
\text { encouraged }\end{array}$ & $64(96.9)$ \\
\hline $\begin{array}{l}\text { High Risk group should be tested } \\
\text { for HIV/AIDS }\end{array}$ & $61(92.4)$ \\
\hline $\begin{array}{l}\text { People do not have same sexual } \\
\text { pleasure with the use of condom }\end{array}$ & $19(28.7)$ \\
\hline LGBT are at high risk for HIV/AIDS & $55(83.3)$ \\
\hline $\begin{array}{l}\text { It is necessary to do blood test } \\
\text { before marriage }\end{array}$ & $56(84.8)$ \\
\hline $\begin{array}{l}\text { People infected with AIDS should } \\
\text { be allowed to use common } \\
\text { rooms }\end{array}$ & $40(60.6)$ \\
\hline $\begin{array}{l}\text { People infected with HIV should } \\
\text { be allowed to work }\end{array}$ & 60 (90.9) \\
\hline $\begin{array}{l}\text { Public education and sex } \\
\text { education is important to } \\
\text { decrease stigma associated } \\
\text { with HIV sufferers and LGBT } \\
\text { population. }\end{array}$ & $61(92.4)$ \\
\hline $\begin{array}{l}\text { I would not kiss someone } \\
\text { suffering from AIDS }\end{array}$ & $14(21.2)$ \\
\hline
\end{tabular}

The relationship of knowledge and socio-demographic characteristics was analyzed by using Pearson's chisquare test which revealed a significant association with training and awareness program regarding HIV/AIDS $(p<0.05)$. Using spearman's correlation, a significant correlation was found between knowledge and attitude of the respondents regarding HIV/AIDS (correlation = $0.304, p=0.012$ ). 


\section{DISCUSSION}

HIV/AIDS is a major problem everywhere and it is even a burning issue among sexual minorities. Due to tough social stigma associated with their sexual orientation, they are not open with their family, friends, and colleagues. In developing countries, where religious values and cultural taboos are extreme, the feeling of disempowerment, prejudice and low self-esteem limits their access to safer sex information, services and reduce their capacity for appropriate sexual decision and make them more susceptible towards fatal diseases like HIV/ AIDS $^{6}$. Therefore, it is very imperative to assess their knowledge and attitude on HIV/AIDS.

In the present study, most of the respondents are young adults belonging to age group 20-25 years. Another study conducted among MSM in Kathmandu Valley also showed similar findings, median age of the respondents being 24 years $^{8}$. Most of them were unmarried which is supported by another study where $48.1 \%$ of the respondents were single, followed by married (46.9\%) and divorced $(5 \%)^{9}$.

The present study illustrates that all the study population is literate which shows evenness with developing educational status of the country. The finding is further supported by another study where almost $43 \%$ of MSM have passed School Leaving Certificate (SLC), followed by $4 \%$ illiterate and $6.8 \%$ could read and write but have no formal schooling ${ }^{8}$.

Many peer/outreach educators, drop-in centres (DIC), health services and organization are providing training and awareness programs regarding HIV/AIDs and its transmission with success ${ }^{10}$. In the present study as well, this impact is reflected where nearly $70 \%$ of the study population has attended such programs.

This study reveals that sex workers are most likely to get infected with HIV/AIDS which is similar with the study done in Armenia that indicates unprotected sexual activity or sexual activities with an infected partner are potential risks ${ }^{11}$.

Nearly $97 \%$ of the respondents knew that HIV/AIDs is transmitted from blood transfusion, sharing of needle, mother to baby and unsafe sex; and is not transmitted from mosquito bite, sharing common room, eating in same utensils and handshaking. The findings are supported with earlier findings of Knowledge, Attitude and Practice (KAP) study ${ }^{12}$.
The controversy exists between whether HIV positive mother should conceive or not. Half of the respondents told that HIV positive mother should not conceive, whereas half of them told that they should. Studies have shown that if antiretroviral drug is used, HIV positive mother can conceive. Also, in contrary, another study states, regardless of antiretroviral drugs, an infected mother infects her baby ${ }^{13}$.

Lesbians are relatively risk free for HIV transmission. The present study supports this belief. Also, findings from another study reveal transgender and bisexual as the most risk groups ${ }^{13}$. In contradictory, a study done in South Africa depicts high prevalence of HIV among lesbians. It is noted that due to fear of discrimination associated with the disclosure of HIV status and sexual orientation, having bisexual partners or involved in rape and transactional sex, lesbians are leading themselves to the risk of HIV infection ${ }^{14}$.

Relatively the study population of the current study has less knowledge on preventive measures than regarding the transmission of HIV/AIDs. The efforts have to be put forward towards the measure for improving knowledge on HIV/AIDs.

The study also showed an association of knowledge with training and awareness program which is similar with a study done among students in Armenia ${ }^{15}$.

This study report will definitely encourage various national government organizations (NGOs), international government organizations (INGOs) and many other social organizations to make an essential effort on HIV/AIDS prevention. This research report will provide information about sexual minorities which is an under discussed topic to general public. This research report can be used as supporting document for better planning of the training and classes regarding HIV/AIDS to LGBT population.

However, the study only concentrates on knowledge and attitude of HIV/AIDS. The practice was not accessed and this is the basic limitation of this study. Therefore, it is recommended on conducting more training on HIV and AIDs related issues focusing on high risk population. An interventional study can be done to see the effectiveness of such programs as well. Also, a comparative study can be done among LGBT populations in terms of knowledge, attitude and practice. 


\section{CONCLUSION}

The significant association with training and awareness program entails that the knowledge regarding HIV/AIDS could be enhanced more by providing various awareness programs and trainings on HIV/AIDS. And when the level of knowledge is increased, it enhances people's attitude towards HIV/AIDS in more positive way.

\section{REFERENCES}

1. AmfAR. Special report on MSM, HIV, and the road to Universal access-How far have we come. 2008:28. Available from: http://www.amfar.org

2. Human Rights Campaign. Working for Lesbian, Gay, Bisexual and Transgender Equal Rights. HRC Issue Brief: HIV/AIDS and the LGBT Community [Internet]. [cited 2013 Jun6]; Available from:http://www.hrc. org/resources/entry/hrc-issue-brief-hiv-aids-andthe-lgbt-community\#_ftn4

3. Valdiserri R. HIV among MSM examined at Conference on Retroviruses and Opportunistic Infections [Internet]. 2013 Mar 8[cited 2014 Jul 17]; Available from: http://blog.aids.gov/2013/03/hivamong-msm-examined-at-croi.html

4. Morison L. The global epidemiology of HIV/AIDS. Oxford Journal. 2001;58(1):7-14.

5. National AIDS Programme. Global AIDS Response Progress 2014 Report. 2014. Available from: http://www.cleantech.com/indexes/the-globalcleantech-innovation-index/2014-report/.

6. Kollman K, Waites $M$. The global politics of lesbian, gay, bisexual and transgender human rights: an introduction. Contemporary politics.2009:15(1):1-17. Available from:http:// dx.doi.org/10.1080/13569770802674188

7. Boehmer U. Twenty years of public health research: Inclusion of lesbian, gay, bisexual and transgender population. American journal of public health. 2002;92:1125-30.

8. New ERA, STD/AIDS Counseling and Training Services. Integrated biological and behavioural survey among men who have sex with men in the Kathmandu valley. Round III summary report.2009:4-8. Available from: http://www.

\section{ACKNOWLEDGEMENT}

The author would like to thank the Ethical Board of Kathmandu Medical College for providing support and facilities for the research. Author would also like to thank program officers of Blue Diamond Society, Parichaya Samaj and Cruiseaids for their help in approaching the target populating and collecting data from them. aidsdatahub.org/sites/default/files/documents/ Summary_Report_MSM_Kathmandu_2009.pdf

9. Jeremy S. It's what you do: most of the men who have sex with men in the south probably don't identify themselves as gay or bisexual. New Internationalist [Internet]. 2000 Oct 1 [cited 2014 Jul 21]:328. Available from: https://www.questia.com/ magazine/1P3-375478081/it-s-what-you-do-mostof-the-men-who-have-sex-with

10. Ayrancu U. AIDS knowledge and attitude in a Turkish population: an epidemiological study. BMC Public Health. 2005. Available from: http://www. biomedcentral.com/1471-2458/5/95

11. Daniel JO. National trends in HIV transmission among minority. Health issues confronting minority men who have sex with men. Springer. 2008;5:15776

12. World Health Organization, United Nations Programme on HIV and AIDS. Report on the global AIDS epidemic. HIV and AIDS estimates and data, 2007 and 2001.2008;1:212-32.

13. National AIDS control organization. HIV sentinel surveillance and HIV estimation; 2006 [cited 2011 Jan 9]; Available from: http://www.nacoon-line.org/ NACO.

14. World Health Organization, United Nations Programme on HIV and AIDS. AIDS epidemic update: 2006 Dec [Internet]. [cited 2011 Jun 21]; Available from: http://www.unaids.org/en/HIV_ data/epi2006

15. Babikian T, Freier MC, Hopkins GL, DiClemente R, McBride D, Riggs M. An assessment of HIV/ AIDS risk in higher education students in Yerevan, Armenia. AIDS and Behavior. Plenum Publishing Corporation. 2004;8(1):47-61. 